\title{
The Effect of Preceding Self-Control on Green Consumption Behavior: The Moderating Role of Moral Elevation
}

\author{
Mei $\mathrm{Li}^{1,2}$ \\ Min Tan ${ }^{1,2}$ \\ Shibei Wang ${ }^{1,2}$ \\ Jin $\mathrm{Li}^{1,2}$ \\ Guanfei Zhang ${ }^{1,2}$ \\ Yiping Zhong (iD) ${ }^{1,2}$ \\ 'Department of Psychology, Hunan \\ Normal University, Changsha, Hunan, \\ People's Republic of China; ${ }^{2}$ Cognition \\ and Human Behavior Key Laboratory of \\ Hunan Province, Changsha, Hunan, \\ People's Republic of China
}

Background: Studies have shown that individuals restrain their egoistic desires to benefit others (eg, the natural world), which require a higher-order psychological process, such as self-control. Therefore, performing a preceding self-control task may subsequently decrease green consumption behavior. However, whether and how moral elevation, which is an important type of positive incidental emotion, moderates the negative effect of exerting selfcontrol on green consumption behavior remains unknown.

Purpose: The present study aimed to examine how exerting self-control and moral elevation influenced green consumption behavior.

Methods: The product choice task that requires participants to make choices between buying environmentally friendly (eco-friendly) and cheaper (self-interest) products is an index of green consumption behavior. In Experiment 1, we adopted the incongruent Stroop task to induce the exertion of self-control, and participants were asked to make choices in the product choice task. In Experiment 2, participants were provided with moral elevating videos to elicit moral elevation during the interval between the Stroop and product choice tasks.

Results: Experiment 1 indicated that, relative to the congruent Stroop task (the control condition), completing the incongruent Stroop task led to less environmentally friendly choices. Experiment 2 indicated that the participants who watched the elevating video in the incongruent Stroop task condition chose environmentally friendly products with greater frequency compared to those who watched the neutral video. Furthermore, the analyses showed that self-reported moral elevation partly moderated the effect of the exertion of selfcontrol on green consumption behavior.

Conclusion: Our findings indicate that the exertion of self-control has a negative effect on green consumption behavior; however, moral elevation can counteract this negative effect of exerting self-control on green consumption behavior.

Keywords: self-control, green consumption behavior, moral elevation, moderating effect

\section{Introduction}

Green consumption behavior is a common pro-environmental behavior in daily life; it refers to the extent to which individuals consider the impact of their own behavior on the environment when they purchase or use products, and refers to them trying to maximize the positive impact, while minimizing the negative impact. ${ }^{1,2}$ Green consumption behavior is often accompanied with some cost to individuals. ${ }^{3-5}$ In particular, people must restrain themselves from buying cheaper products that are
Correspondence: Yiping Zhong Department of Psychology, School of Education Science, Hunan Normal University, No. 36 Lushan Road, Changsha, Hunan, People's Republic of China

$\mathrm{Tel} / \mathrm{Fax}+86$ 73I-88872II/2

Email ypzhong@hunnu.edu.cn 
not environmentally friendly, or spend additional time and incremental effort to restrain their self-interest consumption habits. $^{6,7}$

Numerous studies have shown that individuals restrain their egoistic and self-interest-oriented desires to benefit others (eg the natural world), which requires a higher-order psychological process, such as self-control. ${ }^{8-11}$ For example, Baumgartner et al found that the higher the cortical baseline activation in the right lateral prefrontal cortex of the brain involved in cognitive control and self-control processes, the higher the frequency of everyday pro-environmental behavior. ${ }^{11}$ Moreover, empirical research has shown that proenvironmental attitudes translate into behavior demanding cognitive or psychological resources. ${ }^{10}$ These findings suggest that individuals' pro-environmental behavior, such as green consumption behavior, require self-control or psychological resources; however, little is known about the effect of preceding self-control on green consumption behavior. Thus, in Experiment 1, we aimed to explore the effect of exerting self-control on green consumption behavior.

According to the strength model of self-control, selfcontrol comprises limited inner resources, and if exerting self-control depletes them, there are fewer resources available for subsequent tasks, leading to poor performance for subsequent acts of self-control. ${ }^{12-14}$ Abundant evidence has indicated that individuals in a state of low selfcontrol are prone to engage in impulsive behaviors to satisfy their immediate and self-interest desires - including overeating, crime and violence, smoking, and less prosocial behavior. ${ }^{15-17}$ For example, Jin et al found that individuals with low self-control allocated less money to the other person, decreasing their prosocial behaviors. ${ }^{15}$ Therefore, it is possible that performing a self-control task would subsequently decrease green consumption behavior.

Exerting self-control depletes limited psychological resources and may decrease green consumption behavior. However, the busy and overworked lifestyle in modern society and the everyday situations of self-control (eg pursuing a healthy diet, maintaining marriage loyalty, saving money) often leave people in states of low selfcontrol. $^{11,18,19}$ Thus, it is crucial to explore how to counteract the negative impact of self-control depletions on green consumption behavior. The Broaden-and-Build Theory contends that positive affect broadens the scope of attention and thought-action repertoires and builds personal resources ranging from physical and social resources to intellectual and psychological resources. ${ }^{20-22}$ Prior research has shown that inducing implicit positive emotion has a restorative effect on self-control resources. ${ }^{23}$ Moreover, it is worth noting that positive affect can alleviate ego depletion and restore the performance of subsequent self-control tasks by rebuilding or replenishing self-control or depleted psychological resources. ${ }^{24-26}$ For instance, Shmueli and Prochaska found that positive affect elicited with a video may increase or replenish self-control strength and weaken the detrimental effects of self-control depletion on smoking behavior. ${ }^{27}$

Importantly, empirical studies (involving prosocial behavior) have indicated that positive emotions moderate the negative relationship between exerting self-control and prosocial behaviors. ${ }^{28,29}$ In particular, after completing the incongruent Stroop task (related to self-control), individuals are less likely to be prosocial toward others; however, inducing positive emotion, such as kindness, can counteract this negative effect. ${ }^{30,31}$ Green consumption behavior is considered a type of prosocial behavior. ${ }^{2,32}$ Moral elevation is a self-transcendent positive moral emotion, ${ }^{33,34}$ which is defined as the warm, uplifting emotional feeling that people sometimes experience when they witness benevolent behaviors of others. ${ }^{35,36}$ Prior research has demonstrated that moral elevation is distinct from other positive emotions $;{ }^{37,38}$ compared with other positive emotions, moral elevation is the most effective way to improve pro-environmental behavior. ${ }^{36,39,40}$ However, whether moral elevation could moderate the negative relationship between self-control and green consumption behavior remains unknown. In Experiment 2, we aimed to explore the effect of moral elevation and exerting selfcontrol on pro-environmental behaviors.

\section{Experiment I}

In Experiment 1, we adopted the incongruent Stroop task to induce the exertion of self-control, and used the product choice task to examine the participants' green consumption behavior. ${ }^{41}$ Previous studies have shown that individuals engage in pro-environmental behavior, such as green consumption behavior, requiring self-control or cognitive resources. ${ }^{10,11}$ According to the strength model of selfcontrol, exerting self-control would deplete limited psychological resources, leading to poor performance for subsequent acts of self-control. ${ }^{14}$ Individuals in a state of low self-control tend to choose an option that satisfies their immediate and self-interest desires rather than a long-term altruistic option. ${ }^{19,42}$ Therefore, we hypothesized that compared to the congruent Stroop task condition, the incongruent Stroop task condition inducing the exertion of self-control 
would deplete finite psychological resources, resulting in less green consumption behavior, which would be demonstrated by participants choosing environmentally friendly products with lower frequency.

\section{Material and Methods Participants}

We recruited 80 healthy undergraduates $\left(28 \mathrm{men} ; M_{\text {age }}=\right.$ 21.70 years, $S D=1.73$ ) from Hunan Normal University to participate in the experiment. All the participants were randomly assigned to one of two conditions: the incongruent Stroop task (40 participants, 15 men) and congruent Stroop task (40 participants, 13 men) conditions. After the experiment, they were paid according to the consequences of the product choice task. A power analysis $\left(G^{*}\right.$ Power 3.1$)$ was used to acquire a post hoc calculation of the power of the sample size. ${ }^{43}$ According to the effect size of Experiment 1 (effect size $d=0.74$ ), using the parameters $\alpha=0.05$, sample size group for each group $=40$, and number of groups $=2$, the analysis estimated a power of 0.94 . The results suggested that the sample reached a medium effect size. All participants were right-handed, with a normal or corrected-tonormal vision, and provided informed consent. This study was conducted in accordance with the Declaration of Helsinki and was approved by the ethics committee of Hunan Normal University.

\section{Manipulating the Exertion of Self-Control}

The Color Stroop task is a classic and effective method for reducing subsequent performance on another self-control task. ${ }^{16,44-46}$ We adopted the modified color Stroop task to manipulate the exertion of self-control. ${ }^{15}$ According to prior research, after conducting the Stroop task, people perform worse on subsequent self-control tasks. ${ }^{47,48}$ In the Stroop task, participants were instructed to identify the displayed color of words and to ignore the semantic content of the words (ie GREEN, YELLOW, BLUE, RED). There were two types of Stroop task: the congruent Stroop task and the incongruent Stroop task. In the congruent Stroop task, the displayed color of words was consistent with the meaning of the words (eg "BLUE" was displayed in blue). In the incongruent Stroop task, the displayed color and word meaning was inconsistent (eg "BLUE" was displayed in red). The task consisted of 160 trials with an equal distribution of the four colors. Participants were asked to identify the color of the words and click a mouse on one of the four buttons labeled
"Red," "Green," "Blue," or "Yellow" in white (randomized for each participant), which were displayed below the stimulus area of the screen. In each trial, the word was displayed for $1000 \mathrm{~ms}$, followed by $500 \mathrm{~ms}$ of feedback on whether the response was correct or not. After completing the task, the participants responded to the manipulation check, including assessing the task difficulty using a 7-point scale ranging from 1 (very easy) to 7 (very difficult), while indicating the degree of effort while completing the Stroop task by responding on a 7-point scale ranging from 1 (no effort) to 7 (great effort). ${ }^{49,50}$ They were also asked to rate the extent to which they felt fear, anger, sadness, disgust, pride, and happiness by responding on a 7-point scale ranging from 1 (do not feel at all) to 7 (feel strongly). ${ }^{15}$

\section{Assessment of Green Consumption Behavior}

The product choice task has been proved to be an effective index of green consumption behavior; ${ }^{41,51,52}$ therefore, we used it to examine the participants' green consumption behavior. ${ }^{9,41}$ In the product choice task, participants were presented with two product-choice tasks. In both instances, one alternative was more environmentally friendly than the other, but was also more expensive. They were then asked to indicate which product they would pick if they were to purchase one of these. If participants purchased ecologically products at a higher price, they were considered to be more inclined toward the environmentally friendly consumption option. After completing the Stroop task, participants were presented with a product choice task in which they received five product pairs (see Figure 1). The participants made five choices for the five product pairs; each time they chose an environmentally friendly product, a score of 1 point was gained. The maximum score for choosing environmentally friendly products was five points.

To increase the ecological validity, participants were informed that one of the products that they decided to purchase would be randomly selected at the end of the task, and they would actually purchase this product using part of their participation fee. The critical product categories were air fresheners, paper towels, garbage bags, energy-efficient light bulbs, and detergents (see Table 1). To pretest the price of ecological products, we recruited 33 participants before the formal experiment who were presented with the retail value of a product and were asked how much they were willing to pay for a more environmentally friendly product. We used the median 


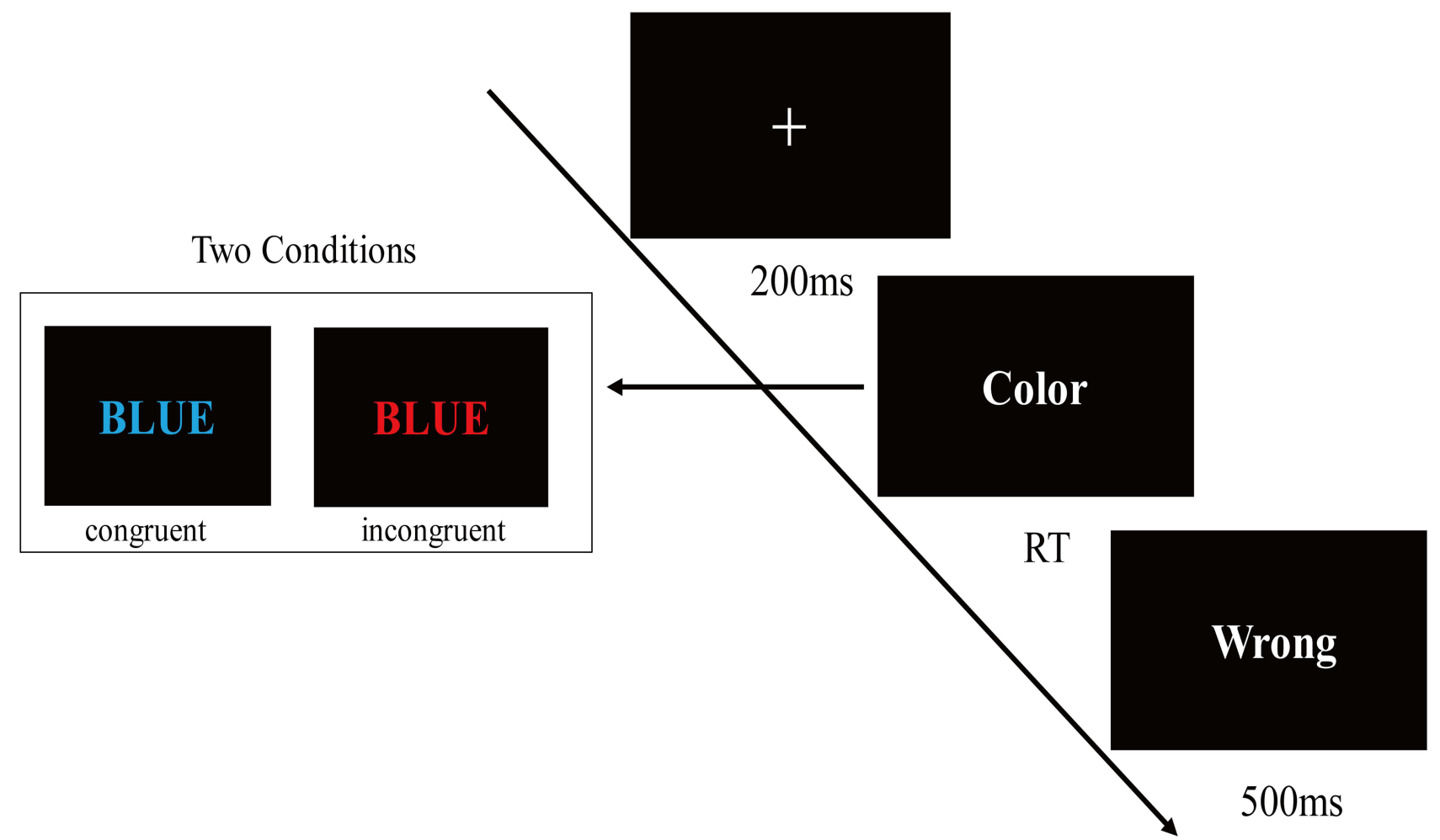

Figure I An illustration of a single trial in the Stroop task. Each trial consists of fixation, a congruent task, or an incongruent task and feedback. After the fixation appears, participants were instructed to identify the displayed color of words and to ignore the semantic content of the words. In the congruent task, the displayed color of words was consistent with the meaning of the words, while in the incongruent task, the displayed color and word meaning were inconsistent. Last, the outcome feedback (right or wrong) was presented for $500 \mathrm{~ms}$.

price that these 33 participants had mentioned for environmentally friendly products in the choice task as the price of the environmentally-friendly products in the formal experiment. ${ }^{41}$

Table I Product Attribute Specifications of the Product Choice Task

\begin{tabular}{|l|c|c|}
\hline Product & Choice A & Choice B \\
\hline Paper towels & $\begin{array}{c}\$ 0.44(¥ 2.9) \\
\text { Non-recycled }\end{array}$ & $\begin{array}{c}\$ 0.58(¥ 3.8 I) \\
100 \% \text { recycled }\end{array}$ \\
\hline $\begin{array}{l}\text { Energy efficient light } \\
\text { bulbs }\end{array}$ & $\begin{array}{c}\$ 0.54(¥ 3.55) \\
\text { Energy saving }\end{array}$ & $\begin{array}{c}\$ 0.32(¥ 2.1) \\
\text { Regular }\end{array}$ \\
\hline Air freshener & $\begin{array}{c}\$ 2.84(¥ 18.58) \\
\text { Environmentally friendly } \\
\text { vaporizer }\end{array}$ & $\begin{array}{c}\$ 2.30(¥ 15) \\
\text { Contains } \\
\text { propellants }\end{array}$ \\
\hline Detergents & $\begin{array}{c}\$ 0.35(¥ 21.9) \\
\text { Regular }\end{array}$ & $\begin{array}{c}\$ 3.84(¥ 25.06) \\
\text { Ecological } \\
\text { packaging }\end{array}$ \\
\hline Garbage bag & $\begin{array}{c}\$ 2.17(¥ \mid 4.21) \\
100 \% \text { recycled }\end{array}$ & $\begin{array}{c}\$ 1.8 I(¥ \mid 1.8) \\
\text { Non-recycled }\end{array}$ \\
\hline
\end{tabular}

\section{Results and Discussion}

\section{Self-Control Exertion Manipulation Checks}

Participants in the incongruent Stroop task condition rated the task as more difficult $(M=2.65, S D=0.58)$ than those in the congruent Stroop task condition $(M=1.70, S D=$ $0.65), t(78)=6.91, p<0.001, \mathrm{~d}=0.74$. In addition, participants in the incongruent Stroop task condition reported that the task required more effort to fight against the urge to select dominant responses $(M=3.30, S D=$ $0.88)$ than those in the control condition $(M=1.80, S D=$ $0.65), t(78)=8.66, p<0.001, \mathrm{~d}=1.92$.

\section{Emotion Checks}

Differences across the incongruent Stroop task condition and the control condition for the seven emotion scores did not approach significance (both $p s>0.05$ ). The $t$-values between the two experimental Stroop task conditions are presented in Table 2.

\section{Product Choice Task}

To examine the effect of the exertion of self-control on green consumption behavior between the two conditions, we performed an independent sample $t$-test on the number 
Table 2 The t-Values for Emotions Between Two Experimental Stroop Task Conditions in Experiment I

\begin{tabular}{|l|c|c|c|c|c|c|}
\hline & Fear & Pride & Anger & Sad & Disgust & Happy \\
\hline$t$ & 1.13 & -0.18 & -0.92 & 1.67 & -0.47 & 1.52 \\
$p$ & 0.27 & 0.86 & 0.36 & 0.10 & 0.64 & 0.13 \\
\hline
\end{tabular}

of ecological choices made in the product choice task. The results indicated that the incongruent Stroop task $(M=$ 2.31, $S D=0.57$ ) led to less environmentally friendly choices than the congruent Stroop task $(M=3.12, S D=$ $1.12), t(68)=-3.84, p<0.01, d=-0.91$, suggesting that exerting self-control subsequently decreased green consumption behavior (see Figure 2).

\section{Discussion}

The results of Experiment 1 indicated that, compared with the congruent Stroop task (the control condition), participants chose environmentally friendly products with lower frequency after they completed the incongruent Stroop task. This result is consistent with the strength model of self-control that posits that exerting self-control depletes individuals limited inner resources and results in poor performance on subsequent tasks that require selfcontrol. $^{13,53}$ Therefore, individuals depleted of selfcontrol resources are inclined to choose self-interest options and decrease green consumption behavior.
Prior studies have found that positive emotions could counteract the negative effect of exerting self-control on prosocial behavior. ${ }^{23,24}$ Moral elevation is the most effective way to improve pro-environmental behavior. ${ }^{20,40}$ However, little is known about whether and how moral elevation moderates the negative effect of exerting selfcontrol on green consumption behavior. Therefore, we explored the effect of moral elevation and exerting selfcontrol on green consumption behavior in Experiment 2.

\section{Experiment 2}

In Experiment 2, we adopted the same paradigms to examine whether moral elevation could moderate the effects of exerting self-control on green consumption behavior (for the mechanism testing method based on regulation, see Spencer, Zanna). ${ }^{54}$ Exerting self-control may deplete limited psychological resources and decrease green consumption behavior. The Broaden-and-Build Theory provides evidence that positive affect can alleviate ego depletion and restore the performance of subsequent

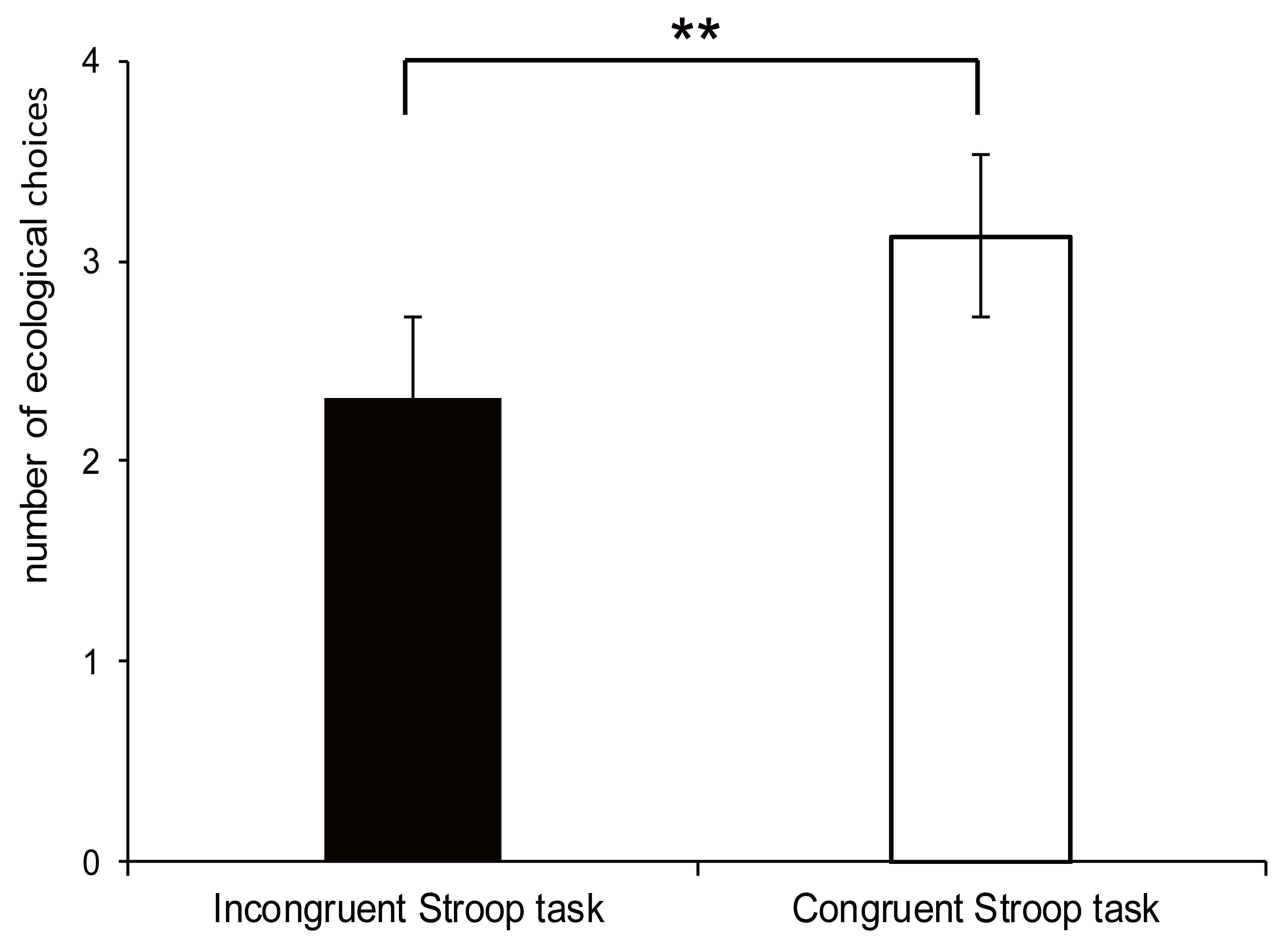

Figure 2 The number of ecological choices made in the incongruent Stroop task condition or congruent Stroop task condition in Experiment I. **p $<0.01$. 
self-control tasks by rebuilding or replenishing more selfcontrol or depleted psychological resources. ${ }^{20,28}$ Moreover, emerging evidence has indicated that positive emotions can alleviate the negative relationship between exerting self-control and prosocial behaviors. ${ }^{29}$ Therefore, we hypothesized that moral elevation would moderate the negative relationship between self-control and green consumption behavior.

\section{Materials and Methods Participants and Design}

We recruited 142 university students (45 men; $M_{\text {age }}=$ 22.38 years, $S D=1.83$ ) from Hunan Normal University to participate in the experiment. A 2 (self-control exertion manipulation: completing the congruent vs incongruent Stroop task) $\times 2$ (emotion prime types: moral elevation vs no-emotion prime) between-subject design was utilized (35 participants were randomly assigned to the incongruent Stroop task condition and moral elevation condition, 37 participants to the incongruent Stroop task condition and no-emotion condition, 36 participants to the congruent Stroop task condition and moral elevation condition, and 34 participants to the congruent Stroop task condition and no-emotion condition). A power analysis ( $\mathrm{G}^{*}$ Power 3.1 ) was used to acquire a post hoc calculation of the power of the sample size. ${ }^{43}$ According to the effect size of Experiment 2 (effect size $f=0.23$ ), using the parameters $\alpha=0.05$, total sample size $=142$, number of groups $=2$, and number of measurements $=2$, the analysis estimated a power of 0.99 . These results suggested that the sample reached to a medium effect size. All participants were right-handed, with a normal or corrected-to-normal vision, and provided informed consent. This study was conducted in accordance with the Declaration of Helsinki and was approved by the ethics committee of Hunan Normal University.

\section{Materials}

Inducing moral elevation by watching moral elevation videos has been shown to be effective previously. ${ }^{34,55,56}$ Based on this, we used a video, ranging from two to five minutes, to induce moral elevation. ${ }^{56}$ To pretest the effectiveness of the moral elevation videos, we recruited 46 undergraduates who did not participate in the experiment to rate the moral elevation and neutral video. The video of moral elevation described a veteran who lived frugally but donated millions of dollars to individuals in need. The neutral video was an instructional video on origami and of the same length as the moral elevation video. ${ }^{57}$ Participants were asked to indicate their agreement with statements (eg "As I watched the video I felt more open toward others") of the 8-item moral elevation scale on a 7-point Likert scale, which was taken from Vianello, Galliani. ${ }^{58}$ We conducted a paired-sample $t$-test to examine the effectiveness of the materials. The rating results indicated that participants who watched the elevating video reported significantly stronger feelings of moral elevation $(M=3.95, S D=0.75)$ than those who watched the neutral video $(M=2.41, S D=0.90), t(46)=-0.89, p<0.001, d=$ -1.26 . These results suggest that a video of moral elevation can successfully induce moral elevation. ${ }^{56}$

\section{Procedure}

The main section of Experiment 2 was composed of three parts. First, participants performed congruent or incongruent Stroop tasks to manipulate self-control. Following this, each participant was asked to rate the extent of their emotional experiences on a 7-point Likert scale, including fear, anger, sadness, disgust, pride, and happiness. Subsequently, participants were provided with different videos to elicit different emotions. In particular, participants in the moral elevation prime condition watched the moral elevating video, while participants in the neutral condition watched the neutral video. After watching the video, participants responded to an 8-item moral elevation scale on a 7 -point Likert-type scale $(1=$ Not at all, $7=$ Extremely). ${ }^{59}$ Finally, each participant was asked to complete the product choice task as in Experiment 1.

\section{Results}

\section{Manipulation Check}

Self-Control Exertion Manipulation Checks

The participants in the incongruent Stroop task condition $(M=4.96, S D=0.97)$ found that the task was more difficult than the participants in the control condition $(M=2.09, S D$ $=0.70), t(140)=20.17, p<0.05$. Moreover, participants in the incongruent Stroop task condition $(M=4.21, S D=$ 1.33) also reported that the task required greater effort than the participants in the control condition $(M=2.72, S D=$ $0.93), t(140)=7.67, p<0.05$.

\section{Emotion Checks}

Differences across the incongruent Stroop task condition and the control condition for the seven emotion scores did not approach significance (both $p s>0.05$ ). The $t$-values 
Table 3 The t-Values for Emotions Between Two Experimental Stroop Task Conditions in Experiment 2

\begin{tabular}{|l|c|c|c|c|c|c|}
\hline & Fear & Pride & Anger & Sad & Disgust & Happy \\
\hline$t$ & -0.92 & -0.56 & -0.07 & 0.74 & -0.46 & 0.97 \\
$p$ & 0.36 & 0.57 & 0.95 & 0.46 & 0.64 & 0.33 \\
\hline
\end{tabular}

between the two experimental Stroop task conditions are presented in Table 3.

\section{Moral Elevation Manipulation Checks}

A significant main effect of emotion prime types on mean moral elevation scores was observed, indicating that participants who watched the elevating video $(M=4.03, S D=$ 0.43 ) reported significantly stronger feelings of moral elevation than those who watched the neutral video $(M=2.87$, $S D=0.72), t(140)=11.5, p<0.05$. These results suggest that the moral elevation manipulation was effective.

\section{Product Choice Task}

A 2 (self-control exertion manipulation: completing the congruent vs incongruent Stroop task) $\times 2$ (emotion prime types: moral elevation prime vs no-emotion prime) analysis of variance (ANOVA) was conducted on the number of ecological choices made in the product choice task. The ANOVA indicated a main effect of the manipulation of exerting self-control, $F(1,138)=19.22, p<0.001, \eta=$ 0.12 , indicating that the incongruent Stroop task $(M=$ $3.03, S D=1.37$ ) led to less environmentally friendly choices than the congruent Stroop task $(M=3.71, S D=0.93)$. There was also a main effect of emotion prime types, $F(1,138)=$
65.77, $p<0.001, \eta=0.32$, suggesting that participants chose environmentally friendly products with greater frequency in the moral elevation condition $(M=4.00, S D=0.85)$ than in the neutral prime condition $(M=2.75, S D=1.22)$.

Importantly, there was a significant interaction effect between the manipulation of exerting self-control and emotion prime types, $F(1,138)=41.78, p<0.001, \eta=$ 0.23 . Simple effect analysis showed that in the incongruent Stroop task, there was a significant difference between the moral elevation condition and neutral prime condition, $F$ $(1,138)=107.72, p<0.001, \eta=0.44$, indicating that participants in the moral elevation condition $(M=4.14$, $S D=0.15$ ) chose environmentally friendly products with greater frequency than those in the neutral prime condition $(M=1.97, S D=0.15)$. However, in the congruent Stroop task, the difference between the moral elevation and neutral prime conditions was not significant, $F(1,138)=1.34$, $p=0.25$ (see Figure 3).

\section{The Moderating Effect of Self-Reported Moral Elevation}

To test for the moderating effect of emotion prime types on pro-environmental behavior, the PROCESS macro (Model

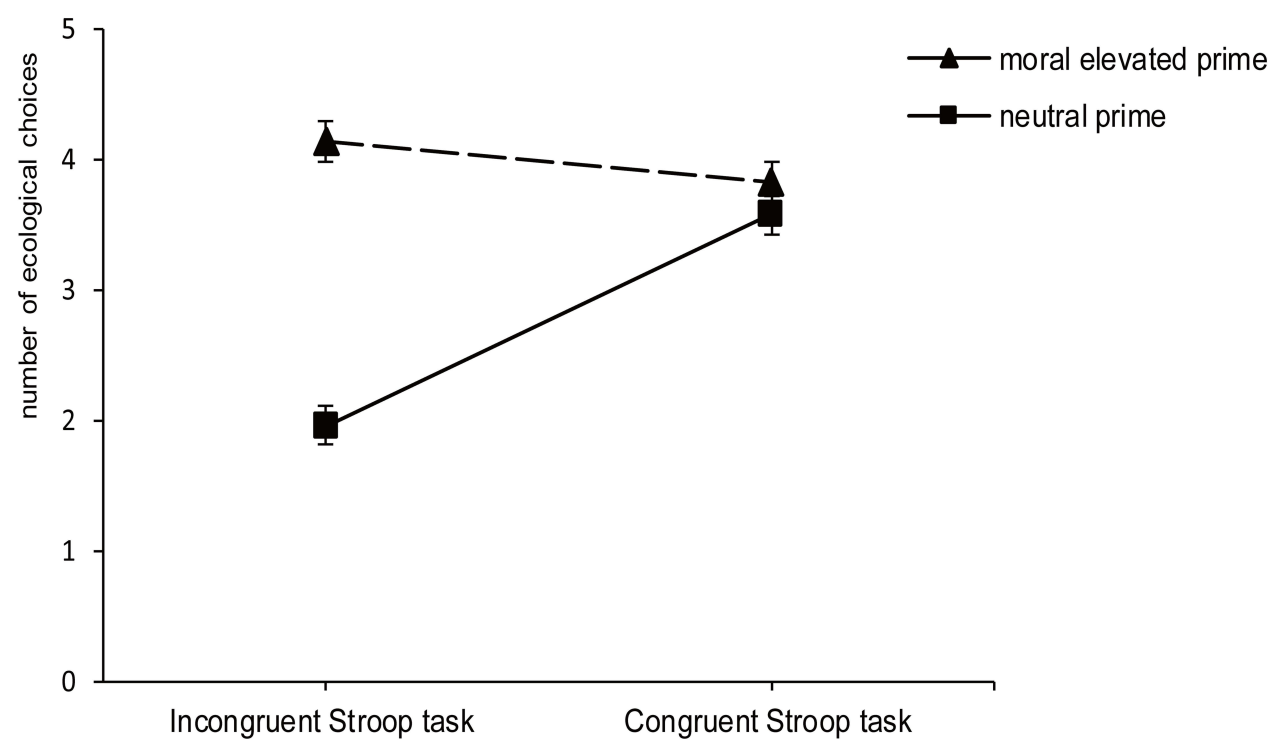

Figure 3 The moderating effect of moral elevation on the relationship between the exertion of self-control and the number of ecological choices in the product choice task of Experiment 2. 


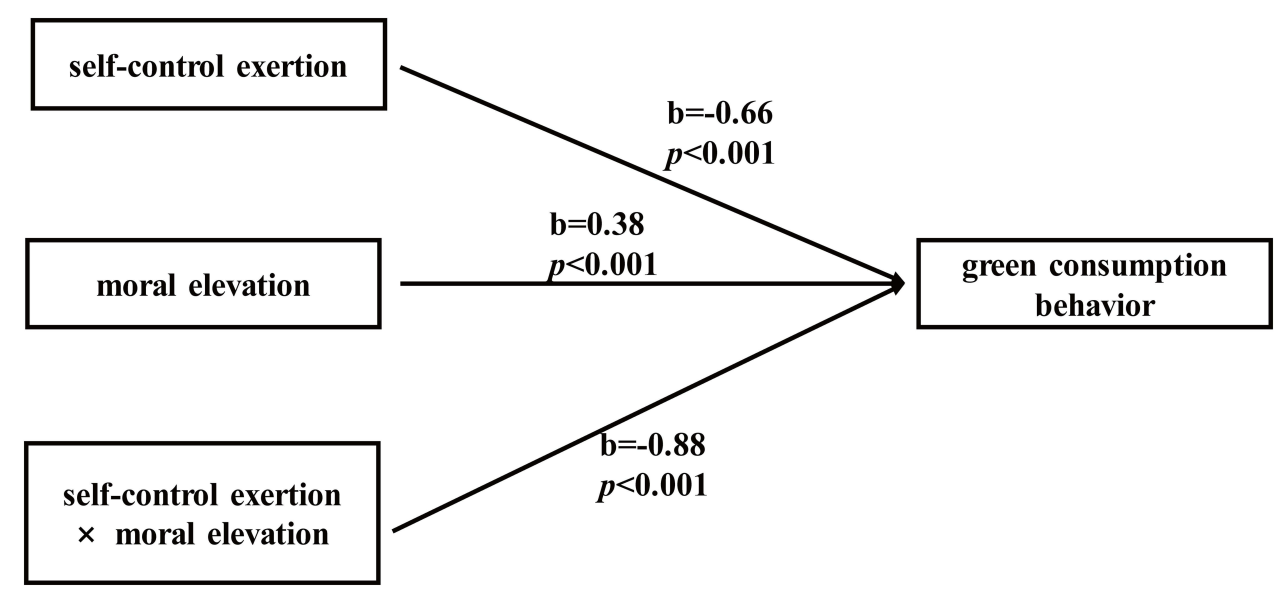

Figure 4 Moderated model: the self-reported moral elevation moderates the effect of the exertion of self-control on the green consumption behavior.

1, 5000 bootstrap samples) for SPSS was employed. ${ }^{60}$ The self-control manipulation conditions $(0=$ the congruent Stroop task, 1 = the incongruent Stroop task) were dummycoded. Moral elevation was used as a continuous variable by using the scores of the moral elevation manipulation checks. The results showed a significant interaction effect $(b=0.88$, $S E=0.22, t=4.00, p<0.01,95 \% \mathrm{CI}=[0.44,1.31], \Delta R^{2}=$ 0.086). Thereafter, we conducted a simple slope analysis. Specifically, self-control exertion negatively predicted the ecological choices of individuals with lower moral elevation levels ( $-1 \mathrm{SD}$ ), $b=-1.39, \mathrm{SE}=0.26, t=-5.42, p<0.001$, $95 \% \mathrm{CI}=[-1.90,-0.88]$, but it could not significantly predict the ecological choices of those with higher moral elevation levels ( $+1 \mathrm{SD}$ ), $b=0.72, S E=0.25, t=0.28, p>$ $0.05,95 \% \mathrm{CI}=[0.78,-0.43]$ (see Figure 4$)$.

\section{Discussion}

In line with our hypothesis, moral elevation moderated the negative relationship between the exertion of self-control and green consumption behavior. After completing the incongruent Stroop task, participants in the moral elevation condition chose environmentally friendly products with greater frequency than those in the neutral prime condition. The moderating effect analysis of self-reported moral elevation provided further evidence that moral elevation was a moderating factor that affected the exertion of self-control on green consumption behavior.

\section{General Discussion}

Our findings provided experimental evidence that selfcontrol has a negative effect on green consumption behavior (Experiment 1). Moreover, moral elevation moderated the negative relationship between the exertion of self- control and green consumption behavior (Experiment 2), such that the detrimental effect of the exertion of selfcontrol was buffered by inducing moral elevation.

\section{Exertion of Self-Control Decreases Green Consumption Behavior}

Both Experiment 1 and 2 found that exerting self-control decreased green consumption behavior. In terms of the strength model of self-control, the initial incongruent Stroop task depleted the finite self-control resources. ${ }^{16,61,62}$ In this case, people may not have the power or resources to restrain their motives of self-interest and may seek immediate desire that meets their selfish impulses. ${ }^{13,63,64}$ For example, empirical studies have showed that individuals with low self-control are more likely to choose an option that meets their immediate desire (eg chocolate cake), rather than a healthier option (eg a fruit salad). ${ }^{19,42}$ The product choice task, which measures green consumption behavior, is regarded as a task that requires the exertion of self-control to restrain selfish impulses (eg saving money), especially when people consider the long-term benefits to the natural environment and choose to protect it. ${ }^{9,41}$ Therefore, after completing the incongruent Stroop task, psychological resources were depleted, and individuals tended to follow their selfish responses, thereby decreasing their green consumption behavior.

\section{The Moderating Effect of Moral Elevation}

As found in previous studies, in Experiment 2, participants in the moral elevation condition exhibited more green consumption behavior than in the neutral prime condition. ${ }^{35,36}$ Studies have suggested that moral elevation can facilitate social bonds and increase individuals' 
feelings of connectedness to the natural world. ${ }^{36,65}$ On the other hand, feelings of moral elevation, elicited by witnessing another person perform a good deed, can motivate individuals to help others, leading to an increase in prosocial behavior. ${ }^{36,66}$ Green consumption behavior is not only an environmentally friendly behavior that can protect the natural world but also a prosocial behavior that can protect other humans. ${ }^{32,67}$ Accordingly, it is reasonable that the participants in the moral elevation prime condition were more willing to sacrifice their interests to buy more expensive environmentally friendly products to benefit the natural world and other humans.

More importantly, individuals in states of low selfcontrol engaged in less green consumption behavior, with moral elevation playing a moderating role in the negative relationship between the exertion of self-control and green consumption behavior. This finding is consistent with the previous studies. ${ }^{15,22,23,29}$ Empirical evidence has indicated that exerting self-control depletes resources and causes individuals to concern about immediate self-interest goals. ${ }^{13,31}$ However, positive emotions or moods can alleviate ego depletion and facilitate self-control. ${ }^{24,29}$ For example, Tice and Baumeister found that after an initial act of self-control, individuals who watched a comedy video or received a surprise gift had improved self-control on subsequent tasks than those who were exposed to a neutral mood stimulus. ${ }^{29}$ Consequently, moral elevation, the most effective positive affect to improve pro-environmental behavior, alleviated the detrimental effects of exerting self-control on green consumption behavior in the present study. ${ }^{36,40}$ Furthermore, according to the Broaden-and-Build Theory, positive affect can replenish self-control resources and weaken the detrimental effects of exerting self-control on subsequent self-control tasks. ${ }^{20,22,23}$ Thus, we speculate that moral elevation may have remarkable power to replenish self-control resources and restore individuals' capacity to exert control and volition.

\section{Theoretical Contribution}

We extended prior research that has shown the impact of self-control and moral elevation on green consumption behavior. In particular, our research verified that the exertion of self-control has a negative effect on green consumption behavior, and moral elevation can counteract this negative effect. Combining our results with those of previous studies, we assume that moral elevation may replenish the psychological resources that were depleted by the initial self-control task. ${ }^{20,22,24}$ These findings support the
Broaden-and-Build Theory to an extent. However, the inner process of how moral elevation counteracts ego depletion and its underlying neural mechanisms should be considered in future studies. Moreover, whether other self-transcendence emotions - such as awe, gratitude, and compassion - can moderate the negative effect of exerting self-control on green consumption behavior can be further explored, ${ }^{40,68}$ and these effects can be compared with the effects of moral elevation found in this study.

\section{Practical Implications}

The findings of the present study shed light on possible interventions of green consumption behavior. In particular, individuals in a state of low self-control were more likely to be dominated by their impulsive system, and tended to choose an option that satisfied their immediate and selfinterest desires rather than the long-term altruistic option, leading to less environmentally friendly choices. Thus, when individuals face a conflicting choice between buying environmentally friendly (eco-friendly) and cheaper (selfinterest) products, policymakers need to avoid having them make such choices in a depleted condition in daily life. Comparatively, temptations, personal goals (including eating healthily) or completing a work task often depletes individuals' limited self-control resources and places them in states of low self-control in their daily life. ${ }^{18,19}$ Thus, it is crucial to seek interventions of green consumption behavior in the state of low self-control. Our study found that moral elevation can counteract the detrimental effects of exerting self-control on green consumption behavior; thus, when individuals are in states of low self-control, policymakers could present moral elevation videos, such as emotionally uplifting stories, to the individuals to promote their green consumption behavior. This may be one of the most important, adaptive, and far-reaching benefits of moral elevation.

\section{Limitations and Future Directions}

Several limitations of the present study should be noted. First, empirical studies have showed that moral elevation is affected by the factors of culture, education, industrialization, wealth, and democracy. ${ }^{56,69}$ Thus, the effect of moral elevation may be differ in different groups or cultural circumstances. Our sample comprised of Chinese college students, thus, it was limited by a homogeneous sample. Future work can further examine the effect of exerting self-control and moral elevation on green consumption behavior for different educated and 
wealthy groups, or in different cultural circumstances. Second, naturalistic experiences of moral elevation by participants may be stronger than experimentally induced moral elevation. ${ }^{56}$ That is, naturalistic experiences of moral elevation may be able to more significantly alleviate the detrimental effect of exerting self-control on green consumption behavior. Thus, future studies could further explore the effect of exerting self-control and naturalistic experiences of moral elevation on green consumption behavior.

\section{Conclusion}

In conclusion, the current findings suggest that the exertion of self-control hindered green consumption behavior in the product choice task. Moreover, moral elevation alleviated the negative effects of the exertion of selfcontrol on green consumption behavior.

\section{Ethical Approval}

The Institutional Review Board of the Hunan Normal University in Hunan approved the study (2021-274).

\section{Acknowledgments}

All authors made a significant contribution to the work reported, whether that is in the conception, study design, execution, acquisition of data, analysis and interpretation, or in all these areas; took part in drafting, revising or critically reviewing the article; gave final approval of the version to be published; have agreed on the journal to which the article has been submitted; and agree to be accountable for all aspects of the work.

\section{Funding}

This work was supported by the major project of National Social Science Foundation of China [grant number: 17ZDA326].

\section{Disclosure}

The authors have declared no competing interests in this work.

\section{References}

1. Lange F, Steinke A, Dewitte S. The Pro-Environmental Behavior Task: a laboratory measure of actual pro-environmental behavior. $J$ Environ Psychol. 2018;56:46-54. doi:10.1016/j.jenvp.2018.02.007

2. Griskevicius V, Tybur JM, Bram VDB. Going green to be seen: status, reputation, and conspicuous conservation. J Pers Soc Psychol. 2010;98 (3):392. doi:10.1037/a0017346
3. White K, Simpson B. When Do (and Don't) normative appeals influence sustainable consumer behaviors? J Mark. 2013;77 (2):78-95. doi:10.1509/jm.11.0278

4. Wu B, Yang Z. The impact of moral identity on consumers' green consumption tendency: the role of perceived responsibility for environmental damage. J Environ Psychol. 2018;59:74-84. doi:10.1016/j. jenvp.2018.08.011

5. Follows SB, Jobber D. Environmentally responsible purchase behaviour: a test of a consumer model. Eur J Mark. 2000;34(5/ 6):723-746. doi:10.1108/03090560010322009

6. Barclay P, Barker JL. Greener Than Thou: people who protect the environment are more cooperative, compete to be environmental, and benefit from reputation. J Environ Psychol. 2020;72:101441. doi:10.1016/j.jenvp.2020.101441

7. Lange F, Brick C, Dewitte S. Green when seen? No support for an effect of observability on environmental conservation in the laboratory: a registered report. $R$ Soc Open Sci. 2020;7(4):190189. doi:10.1098/rsos.190189

8. DeWall CN, Baumeister RF, Gailliot MT, Maner JK. Depletion makes the heart grow less helpful: helping as a function of self-regulatory energy and genetic relatedness. Pers Soc Psychol Bull. 2008;34(12):1653-1662. doi:10.1177/0146167208323981

9. Chuang Y, Xie X, Liu C. Interdependent orientations increase pro-environmental preferences when facing self-interest conflicts: the mediating role of self-control. J Environ Psychol. 2016;46: 96-105. doi:10.1016/j.jenvp.2016.04.001

10. Langenbach BP, Berger S, Baumgartner $T$, Knoch D. Cognitive resources moderate the relationship between pro-environmental attitudes and green behavior. Environ Behav. 2019;52(9):979-995. doi: $10.1177 / 0013916519843127$

11. Baumgartner T, Langenbach BP, Gianotti LRR, Müri RM, Knoch D. Frequency of everyday pro-environmental behaviour is explained by baseline activation in lateral prefrontal cortex. Sci Rep. 2019;9:1. doi:10.1038/s41598-018-36956-2

12. Baumeister RF, Bratslavsky E, Muraven M, Tice DM. Ego depletion: is the active self a limited resource? J Pers Soc Psychol. 1998;74 (5):1252-1265. doi:10.1037/0022-3514.74.5.1252

13. Hagger MS, Wood C, Stiff C, Chatzisarantis NLD. Ego depletion and the strength model of self-control: a meta-analysis. Psychol Bull. 2010;136(4):495-525. doi:10.1037/a0019486

14. Baumeister RF, Tice VDM. The strength model of self-control. Curr Dir Psychol Sci. 2007;16(6):351-355.

15. Jin L, Anke L, Yu S, et al. The effect of preceding self-control on prosocial behaviors: the moderating role of awe. Front Psychol. 2019;10:10. doi:10.3389/fpsyg.2019.00010

16. Baumeister RF, Vohs KD, Tice DM. The strength model of self-control. Curr Dir Psychol Sci. 2007;16(6):351-355.

17. Zhang H, Zhou ZE, Liu Y, Shi Y, Xiao J. Too depleted to control yourself? Effect of customer mistreatment on after-work maladaptive behaviours through self-control capacity impairment. Appl Psychol. 2021;70(4):1464-1597.

18. Milyavskaya M, Berkman ET, De Ridder DTD. The many faces of self-control: tacit assumptions and recommendations to deal with them. Motiv Sci. 2019;5(1):79-85. doi:10.1037/mot0 000108

19. Milyavskaya M, Saunders B, Inzlicht M. Self-control in daily life: prevalence and effectiveness of diverse self-control strategies. J Pers. 2021;89(4):634-651. doi:10.1111/jopy.12604

20. Fredrickson BL, Branigan C. Positive emotions broaden the scope of attention and thought-action repertoires. Cogn Emot. 2005;19 (3):313-332. doi:10.1080/02699930441000238

21. Fredrickson BL. What good are positive emotions? Rev Gen Psychol. 1998;2(3):300-319. doi:10.1037/1089-2680.2.3.300

22. Shamosh NA, Gray JR. The relation between fluid intelligence and self-regulatory depletion. Cogn Emot. 2007;21(8):1833-1843. doi:10. 1080/02699930701273658 
23. Ren J, Hu L, Zhang H, Huang Z. Implicit positive emotion counteracts ego depletion. Soc Behav Pers. 2010;38(7):919-928. doi:10.22 24/sbp.2010.38.7.919

24. Zhu Z, Li J, Zhang B, Li Y, Zhang H. The effect of motivation and positive affect on ego depletion: replenishment versus release mechanism. Int $J$ Psychol. 2017;52(6):445-452. doi:10.1002/ ijop. 12235

25. Fredrickson BL. The role of positive emotions in positive psychology. The broaden-and-build theory of positive emotions. Am Psychol. 2001;56(3):218-226. doi:10.1037/0003-066X.56.3.218

26. Agbaria Q. Internet addiction and aggression: the mediating roles of self-control and positive affect. Int J Ment Health Addict. 2021;19 (4):1227-1242. doi:10.1007/s11469-019-00220-z

27. Shmueli D, Prochaska JJ. A test of positive affect induction for countering self-control depletion in cigarette smokers. Psychol Addict Behav. 2012;26(1):157-161. doi:10.1037/a0023706

28. Dingzhou F, Donghai Q, Xuchen H. The self-control process model of altruistic behavior: the positive effect of moral emotions under the ego depletion. Acta Psychologica Sinica. 2016;48(9):1175-1183. doi:10.3724/SP.J.1041.2016.01175

29. Tice DM, Baumeister RF, Shmueli D, Muraven M. Restoring the self: positive affect helps improve self-regulation following ego depletion. $J$ Exp Soc Psychol. 2007;43(3):379-384. doi:10.1016/j.jesp.20 06.05 .007

30. Li J, Li A, Sun Y, et al. The effect of preceding self-control on prosocial behaviors: the moderating role of awe. Front Psychol. 2019;10:682. doi:10.3389/fpsyg.2019.00682

31. Martinsson P, Myrseth KOR, Wollbrant C. Reconciling pro-social vs. selfish behavior: on the role of self-control. Judgm Decis Mak. 2012;7(3):304-315.

32. Bamberg S, Möser G. Twenty years after Hines, Hungerford, and Tomera: a new meta-analysis of psycho-social determinants of pro-environmental behaviour. J Environ Psychol. 2007;27(1):14-25. doi:10.1016/j.jenvp.2006.12.002

33. Haidt J, Morris JP. Finding the self in self-transcendent emotions. Proc Natl Acad Sci U S A. 2009;106(19):7687-7688. doi:10.1073/ pnas.0903076106

34. Silvers JA, Haidt J. Moral elevation can induce nursing. Emotion. 2008;8(2):291-295. doi:10.1037/1528-3542.8.2.291

35. Monroe A. Moral elevation: indications of functional integration with welfare trade-off calibration and estimation mechanisms. Evol Hum Sci. 2020;41(4):293-302.

36. Schnall S, Roper J, Fessler DMT. Elevation leads to altruistic behavior. Psychol Sci. 2010;21(3):315-320. doi:10.1177/0956797 609359882

37. Thomson AL, Siegel JT. Elevation: a review of scholarship on a moral and other-praising emotion. J Posit Psychol. 2017;12 (6):628-638. doi:10.1080/17439760.2016.1269184

38. Sparks AM, Fessler DMT, Holbrook C. Elevation, an emotion for prosocial contagion, is experienced more strongly by those with greater expectations of the cooperativeness of others. PLoS One. 2019;14(12):1-29. doi:10.1371/journal.pone.0226071

39. Siegel JT, Thomson AL, Navarro MA. Experimentally distinguishing elevation from gratitude: oh, the morality. J Posit Psychol. 2014;9 (5):414-427. doi:10.1080/17439760.2014.910825

40. Zelenski J, Desrochers J. Can positive and self-transcendent emotions promote pro-environmental behavior? Curr Opin Psychol. 2021;42: 31-35. doi:10.1016/j.copsyc.2021.02.009

41. Cornelissen G, Pandelaere M, Warlop L, Dewitte S. Positive cueing: promoting sustainable consumer behavior by cueing common environmental behaviors as environmental. Int J Res Mark. 2008;25 (1):46-55. doi:10.1016/j.ijresmar.2007.06.002

42. Haws K, Davis S, Dholakia U. Salad = success and fries = failure? Conceptualizing and assessing self-control outcome measures in food decision-making research. J Consum Behav. 2016;15(2):99-116. doi:10.1002/cb.1560
43. Faul F, Erdfelder E, Lang A-G, Buchner A. G* Power 3: a flexible statistical power analysis program for the social, behavioral, and biomedical sciences. Behav Res Methods. 2007;39(2):175-191. doi:10.3758/BF03193146

44. Inzlicht M, Gutsell JN. Running on empty: neural signals for self-control failure. Psychol Sci. 2007;18(11):933-937. doi:10.1111/ j.1467-9280.2007.02004.x

45. Bustamante L, Lieder F, Musslick S, Shenhav A, Cohen J. Learning to overexert cognitive control in a stroop task. Cogn Affect Behav Neurosci. 2021;21(3):453-471. doi:10.3758/s13415-020-00845-x

46. Wolff W, Sieber V, Bieleke M, Englert C. Task duration and task order do not matter: no effect on self-control performance. Psychol Res. 2021;85(1):397-407. doi:10.1007/s00426-019-01230-1

47. Dang J. An updated meta-analysis of the ego depletion effect. Psychol Res. 2018;82(4):645-651. doi:10.1007/s00426-01 7-0862-x

48. Dang J, Barker P, Baumert A, et al. A multilab replication of the ego depletion effect. Soc Psychol Personal Sci. 2020;12:14-24.

49. Boucher HC, Kofos MN. The idea of money counteracts ego depletion effects. J Exp Soc Psychol. 2012;48(4):804-810. doi:10.1016/j. jesp.2012.02.003

50. Tops M. Bored but not depleted: PRotective Inhibition of Self-regulation and Motivation (PRISM). Cortex. 2017;96:130-133. doi:10.1016/j.cortex.2017.07.008

51. Lange F, Dewitte S. Measuring pro-environmental behavior: review and recommendations. $J$ Environ Psychol. 2019;63:92-100. doi:10.1016/j.jenvp.2019.04.009

52. Steg L, Bolderdijk JW, Keizer K, Perlaviciute G. An integrated framework for encouraging pro-environmental behaviour: the role of values, situational factors and goals. J Environ Psychol. 2014;38:104-115. doi:10.1016/j.jenvp.2014.01.002

53. Dvorak RD, Simons JS. Moderation of resource depletion in the self-control strength model: differing effects of two modes of self-control. Pers Soc Psychol Bull. 2009;35(5):572-583. doi:10.1177/0146167208330855

54. Spencer SJ, Zanna MP, Fong GT. Establishing a causal chain: why experiments are often more effective than mediational analyses in examining psychological processes. J Pers Soc Psychol. 2005;89 (6):845-851. doi:10.1037/0022-3514.89.6.845

55. Englander ZA, Haidt J, Morris JP. Neural basis of moral elevation demonstrated through inter-subject synchronization of cortical activity during free-viewing. PLoS One. 2012;7(6):e39384. doi:10.1371/ journal.pone.0039384

56. Moreton SG, Arena A, Hornsey MJ, Crimston CR, Tiliopoulos N. Elevating nature: moral elevation increases connectedness to nature. J Environ Psychol. 2019;65:101332. doi:10.1016/j.jenvp.2019.101332

57. Lai CK, Haidt J, Nosek BA. Moral elevation reduces prejudice against gay men. Cogn Emot. 2014;28(5):781-794. doi:10.1080/ 02699931.2013 .861342

58. Vianello M, Galliani EM, Haidt J. Elevation at work: the effects of leaders' moral excellence. J Posit Psychol. 2010;5(5):390-411. doi:10.1080/17439760.2010.516764

59. Van Cappellen P, Saroglou V, Iweins C, Piovesana M, Fredrickson B. Self-transcendent positive emotions increase spirituality through basic world assumptions. Cogn Emot. 2013;27:1378.

60. Hayes AF. Introduction to Mediation, Moderation, and Conditional Process Analysis: A Regression-Based Approach. New York, NY: Guilford Press; 2013.

61. Job V, Dweck CS, Walton GM. Ego depletion-is it all in your head?: implicit theories about willpower affect self-regulation. Psychol Sci. 2010;21(11):1686-1693. doi:10.1177/095679761038 4745

62. Carter EC, Kofler LM, Forster DE, McCullough ME. A series of meta-analytic tests of the depletion effect: self-control does not seem to rely on a limited resource. J Exp Psychol Gen. 2015;144 (4):796-815. doi:10.1037/xge0000083 
63. Baumeister RF, Vohs KD. Chapter two - strength model of selfregulation as limited resource: assessment, controversies, update. In: Olson JM, Zanna MP, editors. Adv Exp Soc Psychol. Vol. 54. Academic Press; 2016:67-127.

64. Baumeister RF, Sparks EA, Stillman TF, Vohs KD. Free will in consumer behavior: self-control, ego depletion, and choice. J Consum Psychol. 2008;18(1):4-13. doi:10.1016/j.jcps.2007.10.002

65. Stellar JE, Gordon AM, Piff PK, et al. Self-transcendent emotions and their social functions: compassion, gratitude, and awe bind us to others through prosociality. Emot Rev. 2017;9(3):200-207. doi:10.1177/1754073916684557

66. Ding W, Shao Y, Sun B, Xie R, Li W, Wang X. How can prosocial behavior be motivated? The different roles of moral judgment, moral elevation, and moral identity among the young Chinese. Front Psychol. 2018;9:814. doi:10.3389/fpsyg.2018.00814
67. Van de Vyver J, Abrams D. Testing the prosocial effectiveness of the prototypical moral emotions: elevation increases benevolent behaviors and outrage increases justice behaviors. J Exp Soc Psychol. 2015;58:23-33. doi:10.1016/j. jesp.2014.12.005

68. Xiang Y, Yuan R. Why do people with high dispositional gratitude tend to experience high life satisfaction? A broaden-and-build theory perspective. J Happiness Stud. 2021;22(6):2485-2498. doi:10.1007/ s10902-020-00310-z

69. Miyamoto Y, Ma X. Dampening or savoring positive emotions: a dialectical cultural script guides emotion regulation. Emotion. 2011;11(6):1346-1357. doi:10.1037/a0025135

\section{Publish your work in this journal}

Psychology Research and Behavior Management is an international, peer-reviewed, open access journal focusing on the science of psychology and its application in behavior management to develop improved outcomes in the clinical, educational, sports and business arenas. Specific topics covered in the journal include: Neuroscience, memory and decision making; Behavior modification and management; Clinical applications; Business and sports performance management; Social and developmental studies; Animal studies. The manuscript management system is completely online and includes a very quick and fair peer-review system, which is all easy to use. Visit http://www. dovepress.com/testimonials.php to read real quotes from published authors. 